\title{
Chronic exposure to arsenic, LINE-1 hypomethylation, and blood pressure: a cross-sectional study in Bangladesh
}

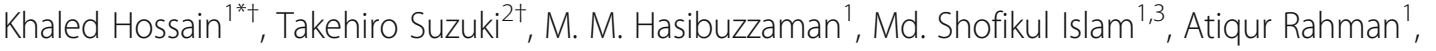 \\ Sudip Kumar Paul1,3, Tanzina Tanu', Shakhawoat Hossain', Zahangir Alam Saud', Mashiur Rahman", \\ Farjana Nikkon ${ }^{1}$, Hideki Miyataka ${ }^{5}$, Seiichiro Himeno ${ }^{5}$ and Keiko Nohara ${ }^{2}$
}

\begin{abstract}
Background: Chronic exposure to arsenic is associated with cancer and hypertension. Growing evidence suggests that altered methylation in long interspersed nuclear element-1 (LINE-1) is involved in many types of disorders, including cardiovascular disease. Here we evaluated the association between arsenic exposure and LINE-1 methylation levels, especially in relation to blood pressure (BP).

Methods: A total of 236 subjects (175 from arsenic-endemic areas and 61 from a non-endemic area) in rural Bangladesh were recruited. The subjects' arsenic exposure levels (i.e., drinking water, hair and nail arsenic concentrations) were measured by inductively coupled plasma mass spectroscopy. The subjects' LINE-1 methylation levels were determined by pyrosequencing.

Results: The average LINE-1 methylation levels of the subjects living in the arsenic-endemic areas were significantly $(p<0.01)$ lower than those of the subjects living in the non-endemic area. In a sex-stratified analysis, the arsenic exposure levels in female but not male subjects showed a significant inverse association with LINE-1 methylation levels before (water arsenic: $p<0.01$, hair arsenic: $p<0.05$, nail arsenic: $p<0.001$ ) and after (water arsenic: $p<0.01$, hair arsenic: $p<0.05$, nail arsenic: $p<0.001$ ) adjustment for age, body mass index and smoking. Analyses examining interactions among arsenic levels, BP and LINE-1 methylation showed that arsenic-related elevated levels of BP were associated with LINE-1 hypomethylation.
\end{abstract}

Conclusions: Our findings demonstrated that chronic exposure to arsenic was inversely associated with LINE-1 methylation levels in blood leukocyte DNA and this was more pronounced in females than males; in addition, the decreased levels of LINE-1 methylation might be involved in the arsenic-induced elevation of BP.

Keywords: Arsenic, LINE-1, Hypomethylation, Blood pressure, Hypertension, Bangladesh

\section{Background}

Arsenic is a potent environmental pollutant and a class I human carcinogen. Chronic exposure to arsenic is a major threat to the public health in many countries, including Bangladesh. Chronic exposure to arsenic has been associated with several neoplastic and nonneoplastic diseases [1-3]. It is estimated that approx.

\footnotetext{
*Correspondence: khossainbio@gmail.com

${ }^{\dagger}$ Equal contributors

'Department of Biochemistry and Molecular Biology, University of Rajshahi, Rajshahi-6205, Bangladesh

Full list of author information is available at the end of the article
}

80-100 million people in Bangladesh are at risk of arsenic toxicity because they are consuming arsenic through drinking water at concentrations greater than the permissive limit $(<10 \mu \mathrm{g} / \mathrm{L})$ set by the World Health Organization (WHO). The arsenic crisis in Bangladesh has been described as the largest mass poisoning of a population in history [4].

Health outcomes of chronic exposure to arsenic are influenced by several genetic and non-genetic factors. The recent development of fine and robust epigenetic techniques and the growing evidence that supports the involvement of epigenetic modifications in cancer and 
other diseases have created great interest in potential epigenetic biomarkers of arsenic-related diseases. Epigenetic changes, especially changes in DNA methylation have been reported to be implicated in the pathogenesis of many diseases [5-9].

DNA methylation is a chemical modification of the genome that involves the covalent addition of a methyl group (mainly to cytosine residues located in CpG dinucleotides), which converts cytosine to 5-methyl cytosine. Most of the methylation of $\mathrm{CpG}$ islands in mammalian genomes is found in transposon elements that include DNA transposons, retrotransposons and endogenous retroviruses. Sequences of these transposable elements may interfere with the regulation of gene expression and genome structure by means of insertions, deletions, and inversions and the translocations of genomic sequences. However, it is believed that transposon activities are decreased by high levels of CpG methylation in transposable elements, which effectively silences these repetitive regions $[10,11]$.

Long interspersed nuclear element-1 (LINE-1) is a member of LINE family of non-long-terminal retrotransposons, and it is the most abundant retrotransposon found in the human genome, accounting for $20 \%$ of the human genome. Growing evidence suggests that hypomethylation in repetitive sequences of DNA such as LINE-1and ALU is associated with various pathophysiological conditions including cardiovascular disease (CVD) [5, 12-17]. Elevated blood pressure (BP) or hypertension is a potent risk factor for CVD, which is the main cause of mortality worldwide. We and other groups have shown that chronic exposure to arsenic is associated with hypertension and circulating biomarkers of CVD [18, 19].

Several population-based studies have identified a link between arsenic exposure and global methylation status; however, the results of these studies are not consistent $[14,20-32]$. Most of the previous studies did not show the pathophysiological relevance of the arsenic exposure-related altered DNA methylation status, and thus the pathophysiological consequences of arsenicrelated changes in the DNA methylation status have remained poorly understood. The main objective of this study was to explore the association between arsenic exposure and LINE-1 methylation levels recruiting human subjects from arsenic-endemic and non-endemic areas in rural Bangladesh. We also wished to examine whether the altered levels of LINE-1 methylation were linked to arsenic-related BP.

\section{Methods}

\section{Study areas and subjects}

Ethical permission was obtained from The University of Rajshahi, Institute of Biological Sciences, Bangladesh (\#32/320-IAMEBBC/IBSc) and National Institute for
Environmental Studies in Japan (\#2013-2R). The human subjects who participated in this study gave their written consent. The arsenic-endemic and non-endemic areas and study subjects were selected as described [18, 33-38]. Arsenic-endemic study areas were selected from the north-west region of Bangladesh that included Marua in Jessore, Dutpatila, Jajri, Vultie and Kestopur in Chuadanga and Bheramara in Kushtia districts. Chowkoli, a village in Naogaon district with no history of arsenic contamination was selected as the non-endemic area. Adults (18-60 years old) who had lived for at least the last 5 years in the arsenic-endemic or non-endemic areas were recruited.

We attempted to match as much as possible the age, sex and socioeconomic parameters of the arsenicendemic and non-endemic subjects. The ratio of endemic and non-endemic subjects was approx. 3:1, and the male-to-female ratios in both the endemic and nonendemic areas were approx. 1:1. The subjects in both the arsenic-endemic and non-endemic areas were villagers, and the socioeconomic parameters such as occupation, monthly income and education levels were very closely matched among the areas. The subjects were asked to convene at a convenient location in their respective areas (irrespective of the visible presence of skin symptoms) for enrollment and initial screening purposes. Many people in the arsenic-endemic areas were found to have skin lesions such as melanosis, hyperkeratosis and hard patches on the palms of the hand and soles of the feet. The individuals who did exhibit symptoms were first identified by a physician, and were then confirmed by a dermatologist. The physician carefully examined various parts of the body to confirm the presence of skin lesions caused by exposure to arsenic.

Pregnant and lactating women, individuals who were hepatitis B-positive, and individuals with a history of drug addiction, chronic alcoholism, prescription for hepatotoxic or antihypertensive medication, malaria, kala azar (leishmaniasis), or hepatic, renal or cardiac diseases were excluded from the study. An interview of each subject was carried out by the trained members of our research team who visited each household and used a standard questionnaire. Information obtained from the interview included the sources of water for drinking and daily household uses, water consumption history, socioeconomic status, occupation, food habit, cigarette smoking habit, alcohol intake, personal and family medical histories, history of diseases, physiological complications, previous physician's reports, and body mass index (BMI).

\section{Water collection and arsenic analysis}

Water samples were collected from the tube wells which the subjects used as a primary source of drinking water, as described [33]. The total arsenic concentration in water samples was determined by inductively coupled 
plasma mass spectroscopy (ICP-MS) after the addition of a solution of yttrium (10 ppb in $1.0 \%$ nitric acid) as an internal standard for the ICP-MS analysis. The accuracy of the ICP-MS determination of the water arsenic concentrations was confirmed by using 'River water'(NMIJ CRM 7202-a No.347; National Institute of Advanced Industrial Science and Technology, Japan) as a certified reference material (CRM). The average value (mean $\pm \mathrm{SD}$ ) of arsenic in the 'River water' determined in triplicate by an ICP-MS analysis was $1.06 \pm 0.04 \mu \mathrm{g} / \mathrm{L}$ (reference value, $1.18 \mu \mathrm{g} / \mathrm{L}$ ).

\section{Hair and nail collections and arsenic analysis}

Hair and toe nails of the subjects were collected and washed as described [33]. The washed samples were allowed to dry at $60{ }^{\circ} \mathrm{C}$ overnight and then digested with concentrated nitric acid using a hot plate at $70{ }^{\circ} \mathrm{C}$ for $15 \mathrm{~min}$ and $115^{\circ} \mathrm{C}$ for $15 \mathrm{~min}$. After cooling, the samples were diluted with $1.0 \%$ nitric acid containing yttrium (10 ppb). The concentrations of arsenic and yttrium in these samples were determined by ICP-MS (HP-4500, Agilent Technologies, Kanagawa, Japan). All samples were determined in triplicate and the average values were used. The accuracy of the arsenic measurement was verified by using the CRM“human hair" (GBW09101, Shanghai Institute of Nuclear Research Academia Sinica, China). The average value of arsenic in "human hair" determined in triplicate followed by an ICP-MS analysis was $0.61 \pm$ $0.12 \mu \mathrm{g} / \mathrm{g}$ (reference value, $0.59 \mu \mathrm{g} / \mathrm{g}$ ).

\section{BP measurement}

The WHO standard protocol for measuring BP was used. After the subject had rested for $\geq 20 \mathrm{~min}$, both systolic and diastolic blood pressures (SBP and DBP) were measured three times with a mercury sphygmomanometer with the subject sitting. SBP and DBP were defined at the first-and fifth-phase Korotkoff sounds, respectively. The average of three measurements was used for the analysis. Hypertension was defined as an SBP value of $\geq 140 \mathrm{mmHg}$ and a DBP value of $\geq 90 \mathrm{mmHg}$ on three repeated measurements.

\section{Blood collection and extraction of DNA}

Peripheral blood was collected from each subject as described [33]. Fasting blood samples $(5-7 \mathrm{~mL})$ were collected in EDTA-containing blood collection tubes from each individual by venipuncture as described [18, 37]. From the EDTA-treated blood, $100 \mu \mathrm{l}$ was taken and DNA was extracted with the use of a DNeasy Blood and Tissue kit (Qiagen, Valencia, CA, USA) according to the manufacturer's recommendations. Extracted DNA was kept at $-20{ }^{\circ} \mathrm{C}$. Because whole blood DNA was predominantly derived from leukocytes, we refer to the whole blood DNA as leukocyte DNA here in.

\section{Measurement of LINE-1 DNA methylation}

Genomic DNA was digested with EcoRI. The bisulfite conversion of DNA was carried out using the EZ-96 DNA Methylation-Gold ${ }^{\text {TM }}$ kit (Zymo Research, Irvine, CA) according to the manufacturer's recommendations. We conducted a polymerase chain reaction (PCR) amplification of bisulfite-modified DNA using a set of forward primer 5' -TTTTGAGTTAGGTGTGGGATATA $-3^{\prime}$ and reverse biotinylatedprimers5' -Biotin-AAAATCA AAAAATTCCCTTTC-3' as reported [24]. The conditions were as follows: $95^{\circ} \mathrm{C}$ for $5 \mathrm{~min}$, and then 50 cycles of $95{ }^{\circ} \mathrm{C}$ for $30 \mathrm{~s}, 50{ }^{\circ} \mathrm{C}$ for $30 \mathrm{~s}$, and $72{ }^{\circ} \mathrm{C}$ for $45 \mathrm{~s}$, and finally $72{ }^{\circ} \mathrm{C}$ for $5 \mathrm{~min}$.

To measure the methylation level of each of the first three CpG sites next to the pyrosequencing primer, we performed sequencing of the PCR product by pyrosequencing using the PyroMark Q96 ID System (Qiagen) according to the manufacturer's recommendations. The pyrosequencing primer for LINE-1 was 5'-GGGTGGGA GTGAT-3'. We extracted the methylation level at each CpG site by using PyroMark Q96 software, ver.2.5.8 (Qiagen). The average methylation level of the first three LINE-1 CpG sites was used as the LINE-1 methylation level.

\section{Statistical analyses}

The statistical analyses were conducted with the Statistical Package for the Social Sciences (SPSS ver. 21.0, SPSS, Chicago, IL). A $p$-value $<0.05$ was considered significant. The normality of the distribution of variables was verified by a Q-Q plot. Because of the skewed distributions of the arsenic exposure metrics, we used log-transformed (natural $\log$ ) values for the statistical analysis. The differences in descriptive characteristics, arsenic exposure levels and other characteristics between the residents of the arsenic-endemic and non-endemic areas were analyzed by an independent sample $t$-test for continuous variables and the Chi-square test for categorical variables. A nonparametric Kruskal-Wallis test was used to analyze the differences in inter-quartile range (IQR) between the subjects in the arsenic-endemic and non-endemic areas.

We performed a multiple linear regression analysis to examine the effects of age, sex, BMI and smoking on the association between arsenic exposure metrics and LINE1 methylation levels. To determine the association and the effects of the variables, we obtained the unadjusted $R^{2}$ and adjusted $R^{2}$ values. $\Delta R^{2}$ values were calculated by subtracting the unadjusted $R^{2}$ from the adjusted $R^{2}$. Finally, we performed multivariate regression analyses to examine the interactions between arsenic exposure, BP and LINE-1 methylation, and to assess the effects of age, sex, BMI and smoking on the associations of arsenic exposure and LINE-1 methylation levels with BP. 


\section{Results}

Table 1 summarizes the descriptive characteristics of the subjects in the arsenic-endemic $(n=175)$ and nonendemic areas $(n=61)$. Of the 236 subjects, 125 were males and 111 were females. Since we attempted to match the subjects' age, sex and socioeconomic parameters (occupation, monthly income and education) between the residents of the arsenic-endemic and nonendemic areas, no significant differences were observed in those parameters between the two groups. Most of the male subjects were farmers, and most of the female subjects were housewives. We did not identify any female smokers, as generally Bangladeshi women do not

Table 1 Demographic characteristics of the study populations in arsenic-endemic and non-endemic areas

\begin{tabular}{|c|c|c|c|c|}
\hline Parameter & All & Non-endemic & Arsenic-endemic & $p$-value \\
\hline Subjects (n) & 236 & 61 & 175 & \\
\hline \multicolumn{5}{|l|}{$\operatorname{Sex}(n)$} \\
\hline Male & 125 & 33 & 92 & \\
\hline Female & 111 & 28 & 83 & \\
\hline Age $(y r s .)^{a}$ & $35.69 \pm 10.13$ & $33.92 \pm 9.18$ & $36.30 \pm 10.40$ & $0.114^{*}$ \\
\hline $\mathrm{IQR}$ & $28.00-43.74$ & $27.00-40.00$ & $28.00-45.00$ & $0.079^{\ddagger}$ \\
\hline BMI $\left(k g / m^{2}\right)^{a}$ & $20.94 \pm 3.57$ & $20.76 \pm 2.77$ & $21.00 \pm 3.82$ & $0.655^{*}$ \\
\hline $\mathrm{IQR}$ & $18.54-22.57$ & $18.71-22.51$ & $18.37-23.00$ & $0.922^{\ddagger}$ \\
\hline \multicolumn{5}{|l|}{ Occupation [n, (\%)] } \\
\hline Male & & & & $0.795^{\dagger}$ \\
\hline Farmers & $97(77.60)$ & $24(72.70)$ & $73(79.30)$ & \\
\hline Business & $5(4.00)$ & $1(3.00)$ & $4(4.30)$ & \\
\hline Students & $5(4.00)$ & $2(6.10)$ & $3(3.30)$ & \\
\hline Worker & $10(8.00)$ & $4(12.30)$ & $6(6.50)$ & \\
\hline${ }^{+}$Others & $8(6.40)$ & $2(6.10)$ & $6(6.50)$ & \\
\hline Female & & & & $0.194^{\dagger}$ \\
\hline Housewives & $105(94.60)$ & $25(89.3)$ & $80(96.40)$ & \\
\hline Students & $4(3.60)$ & $2(7.10)$ & $2(2.40)$ & \\
\hline${ }^{\ddagger}$ Others & $2(1.80)$ & $1(3.60)$ & $1(1.20)$ & \\
\hline \multicolumn{5}{|l|}{ Education [n, (\%)] } \\
\hline No formal education & $142(60.20)$ & $31(50.82)$ & $111(63.43)$ & $0.138^{\dagger}$ \\
\hline Primary & $66(28.00)$ & $18(29.51)$ & $48(27.43)$ & \\
\hline Secondary & $19(8.10)$ & $8(13.11)$ & $11(6.30)$ & \\
\hline Higher & $9(3.80)$ & $4(6.60)$ & $5(2.90)$ & \\
\hline $\begin{array}{l}\text { Income/month } \\
(\text { US\$) }\end{array}$ & $23.45 \pm 10.41$ & $22.67 \pm 8.89$ & $23.72 \pm 10.89$ & $0.457^{*}$ \\
\hline \multicolumn{5}{|l|}{ Smoking in male [n, (\%)] } \\
\hline Yes & $43(34.40)$ & $13(39.40)$ & $30(32.60)$ & $0.309^{\dagger}$ \\
\hline No & $82(65.60)$ & $20(60.60)$ & $62(67.40)$ & \\
\hline Alcohol intake & - & - & - & - \\
\hline
\end{tabular}

BMI was calculated as body weight $(\mathrm{kg})$ divided by height squared $\left(\mathrm{m}^{2}\right)$ Abbreviation: As arsenic, $B M I$ body mass index, IQR inter-quartile range ${ }^{a}$ mean \pm SD

${ }^{*} p$-, ${ }^{\neq} p$-and ${ }^{\dagger} p$-values were obtained by an independent sample $t$-test Kruskal-Wallis test and Chi-square test, respectively. ${ }^{+}$Others included village doctor, security guard, banker and worker. ${ }^{\ddagger}$ Others included farmer smoke. None of the subjects drank alcohol because of the social and religious restrictions on alcohol in Bangladesh.

Table 2 shows the arsenic exposure levels and other characteristic of the subjects. The average concentrations of arsenic in the drinking water, hair and nails of the subjects in the arsenic-endemic areas were approx.70, 8 and 6 times higher, respectively, than those of the subjects in the non-endemic area. The comparison of the arsenic exposure levels between the males and females living in the arsenic-endemic areas showed that the average concentrations of arsenic in the drinking water, hair and nails were slightly higher in the females than the males, although the differences were not significant. Approximately $75 \%$ of the subjects in the arsenic-endemic areas showed skin symptoms, whereas none of the subjects in the non-endemic areas did.

The levels of DBP and SBP of the subjects in the arsenic-endemic areas were significantly $(p<0.001)$ higher than those of the subjects in the non-endemic area, as we reported [18, 35, 37]. Accordingly, the percentage of hypertensive subjects was also higher in the arsenic-endemic areas compared to the non-endemic area. When the levels of DBP and SBP and the percentage of hypertensive subjects were compared between males and females within the arsenic endemic areas, the SBP levels and the percentage of hypertensive patients were significantly higher in the females compared to the males. The differences in DBP and SBP between the arsenic-endemic and non-endemic areas were much greater in the females than the males.

As shown in Table 2, no significant differences in LINE-1 methylation levels were observed in the male subjects between those living in the arsenic-endemic areas and the non-endemic area. In the female subjects, however, the average levels of LINE-1 methylation were $64.23 \pm 2.38$ and $65.92 \pm 1.66$ in the arsenic-endemic and non-endemic areas respectively, and the difference was significant $(p<0.01)$. These data suggest that the association between arsenic exposure and LINE-1 hypomethylation is more pronounced in females than males.

Table 3 shows the results of the multiple linear regression analyses regarding the association between arsenic exposure and LINE-1 methylation levels. For all subjects, the non-adjusted associations between arsenic exposure and LINE-1 methylation were significantly negative $\left(R^{2}=0.033,95 \% \mathrm{CI}=-0.241,-0.043, p<0.01\right.$ for water arsenic; $R^{2}=0.019,95 \% \mathrm{CI}=-0.378,-0.014, p<0.05$ for hair arsenic; and $R^{2}=0.054,95 \% \mathrm{CI}=-0.595,-0.179, p<$ 0.001 for nail arsenic). After adjustment for age, BMI and smoking, the associations between arsenic exposure and LINE-1 methylation levels remained significant $\left(R^{2}=\right.$ $0.057,95 \% \mathrm{CI}=-0.238,-0.038, p<0.01$ for water arsenic; $R^{2}=0.045,95 \% \mathrm{CI}=-0.382,-0.014, p<0.05$ for 
Table 2 Arsenic exposure levels and other characteristics of the subjects in the arsenic-endemic and non-endemic areas

\begin{tabular}{|c|c|c|c|c|}
\hline Parameter & All & Non-endemic & Arsenic-endemic & $p$-value \\
\hline Subjects (n) & 236 & 61 & 175 & \\
\hline \multicolumn{5}{|l|}{ Drinking water As $(\mu \mathrm{g} / \mathrm{L})^{\mathrm{b}}$} \\
\hline Total subjects & $17.76(15.16)$ & $0.76(5.49)$ & $53.39(7.90)$ & $<0.001^{*}$ \\
\hline Males & $13.28(19.90)$ & $0.60(4.96)$ & $40.22(9.02)$ & $<0.001^{*}$ \\
\hline Females & $24.66(13.97)$ & $0.98(6.10)$ & $73.09(6.52)$ & $<0.001^{*}$ \\
\hline$p$-value (between male \& female groups) & $0.081^{*}$ & $0.269^{*}$ & $0.056^{*}$ & \\
\hline \multicolumn{5}{|l|}{ Hair As $(\mu g / g)^{b}$} \\
\hline Total subjects & $1.28(4.43)$ & $0.25(2.38)$ & $2.08(3.54)$ & $<0.001^{*}$ \\
\hline Males & $1.08(4.80)$ & $0.19(2.15)$ & $1.99(3.70)$ & $<0.001^{*}$ \\
\hline Females & 1.39 (3.99) & $0.36(2.40)$ & $2.20(3.38)$ & $<0.001^{*}$ \\
\hline$p$-value (between male \& female groups) & $0.191^{*}$ & $<0.01^{*}$ & $0.604^{*}$ & \\
\hline \multicolumn{5}{|l|}{ Nail As $(\mu \mathrm{g} / \mathrm{g})^{\mathrm{b}}$} \\
\hline Total subjects & $3.40(3.53)$ & $0.96(2.43)$ & $5.29(2.96)$ & $<0.001^{*}$ \\
\hline Males & $3.19(3.41)$ & $1.05(2.32)$ & $4.73(3.00)$ & $<0.001^{*}$ \\
\hline Females & $3.67(3.78)$ & $0.85(2.58)$ & $5.98(2.98)$ & $<0.001^{*}$ \\
\hline$p$-value (between male \& female groups) & $0.403^{*}$ & $0.367^{*}$ & $0.155^{*}$ & \\
\hline \multicolumn{5}{|l|}{ Skin symptoms [n, (\%)] } \\
\hline (+) symptom & $132(55.90)$ & $0(0.0)$ & $132(75.40)$ & $<0.001^{\dagger}$ \\
\hline$(-)$ symptom & $104(44.10)$ & $61(100.0)$ & $43(24.60)$ & \\
\hline \multicolumn{5}{|l|}{$\mathrm{DBP}(\mathrm{mm} \mathrm{Hg})^{a}$} \\
\hline Total subjects & $77.11 \pm 11.84$ & $71.97 \pm 9.89$ & $78.90 \pm 11.96$ & $<0.001^{*}$ \\
\hline Males & $76.73 \pm 10.51$ & $73.33 \pm 8.26$ & $77.95 \pm 10.99$ & $<0.05^{*}$ \\
\hline Females & $77.54 \pm 13.21$ & $70.36 \pm 11.46$ & $79.96 \pm 12.93$ & $<0.01^{*}$ \\
\hline$p$-value (between male \& female groups) & $0.608^{*}$ & $0.245^{*}$ & $0.269^{*}$ & \\
\hline \multicolumn{5}{|l|}{$\operatorname{SBP}(m m ~ H g)^{a}$} \\
\hline Total subjects & $118.72 \pm 18.01$ & $111.18 \pm 14.22$ & $121.35 \pm 18.48$ & $<0.001^{*}$ \\
\hline Males & $116.56 \pm 14.83$ & $112.88 \pm 10.91$ & $117.88 \pm 15.83$ & $0.097^{*}$ \\
\hline Females & $121.16 \pm 20.83$ & $109.18 \pm 17.30$ & $125.20 \pm 20.45$ & $<0.001^{*}$ \\
\hline$p$-value (between male \& female groups) & $0.055^{*}$ & $0.334^{*}$ & $<0.01^{*}$ & \\
\hline \multicolumn{5}{|l|}{ Hypertension [n, (\%)] } \\
\hline \multicolumn{5}{|l|}{ Total subjects } \\
\hline Yes & $32(13.60)$ & $3(4.90)$ & $29(16.60)$ & $<0.05^{\dagger}$ \\
\hline No & $204(86.40)$ & $58(95.10)$ & $146(83.40)$ & \\
\hline \multicolumn{5}{|l|}{ Males } \\
\hline Yes & $10(8.00)$ & $0(0.0)$ & $10(10.90)$ & $<0.05^{\dagger}$ \\
\hline No & $115(92.00)$ & $33(100.0)$ & $82(89.10)$ & \\
\hline \multicolumn{5}{|l|}{ Females } \\
\hline Yes & $22(19.80)$ & $3(10.70)$ & $19(22.90)$ & $0.162^{\dagger}$ \\
\hline No & $89(80.20)$ & $25(89.30)$ & $64(77.10)$ & \\
\hline$p$-value (between male \& female groups) & $<0.01^{\dagger}$ & $0.054^{\dagger}$ & $<0.05^{\dagger}$ & \\
\hline
\end{tabular}


Table 2 Arsenic exposure levels and other characteristics of the subjects in the arsenic-endemic and non-endemic areas (Continued)

\begin{tabular}{|c|c|c|c|c|}
\hline \\
\hline \\
\hline \multicolumn{5}{|l|}{$\begin{array}{l}\text { LINE-1 Methylation level (\%) } \\
\text { Total subjects } \\
\text { Males }\end{array}$} \\
\hline \multirow{2}{*}{$\begin{array}{l}\text { Females } \\
p \text {-value (between male \& female groups) }\end{array}$} & $64.65 \pm 2.33$ & $65.92 \pm 1.66$ & $64.23 \pm 2.38$ & $<0.01^{*}$ \\
\hline & $<0.05^{*}$ & $0.372^{*}$ & \multicolumn{2}{|l|}{$<0.01^{*}$} \\
\hline
\end{tabular}

${ }^{\mathrm{a}}$ Mean \pm SD. ${ }^{\mathrm{b}}$ Geometric mean (GSD) for log-transformed value

${ }^{*} p$ - and ${ }^{\dagger} p$-values were obtained by independent sample $t$-test and Chi-square test, respectively

hair arsenic; and $R^{2}=0.079,95 \% \mathrm{CI}=-0.591,-0.175, p$ $<0.001$ for nail arsenic).

Since we observed a sex-based difference in LINE-1 methylation (Table 2), we performed sex-specific analyses. Intriguingly, we found that the drinking water, hair and nail arsenic concentrations of the female subjects showed significant inverse associations with LINE-1 methylation both before $\left(R^{2}=0.079,95 \% \mathrm{CI}=-0.410\right.$, $-0.088, p<0.01$ for water arsenic; $R^{2}=0.043,95 \% \mathrm{CI}=$ $-0.662,-0.038, p<0.05$ for hair arsenic; and $R^{2}=$ $0.100,95 \% \mathrm{CI}=-0.862,-0.236, p<0.01$ for nail arsenic) and after $\left(R^{2}=0.085,95 \% \mathrm{CI}=-0.407,-0.081\right.$, $p<0.01$ for water arsenic $; R^{2}=0.053,95 \% \mathrm{CI}=-0.664$, -0.037, $p<0.05$ for hair arsenic; and $R^{2}=0.106,95 \%$ $\mathrm{CI}=-0.858,-0.224, p<0.01$ for nail arsenic) adjustment for covariates. No significant associations were observed in the male subjects.
Table 4 shows the associations of arsenic exposure with BP with and without adjustment for LINE-1 methylation levels through multivariate linear regression analyses. In all subjects and in the female subjects, the water, hair and nail arsenic concentrations showed significant associations with DBP and SBP without adjustment for LINE-1 methylation. However, after adjustment with LINE-1 methylation, the associations between arsenic exposure and DBP and SBP were weakened in all subjects, and the associations completely disappeared in the female subjects.

Additional file 1 shows the associations between the arsenic exposure metrics and LINE-1 methylation levels with BP after adjustment for age, sex, BMI and smoking. The adjusted association between arsenic exposure levels and BP, and that between LINE-1 methylation levels and $\mathrm{BP}$ were found to be significant.

Table 3 Associations of arsenic exposure metrics with LINE-1 methylation levels

\begin{tabular}{|c|c|c|c|c|c|c|}
\hline \multirow{3}{*}{$\begin{array}{l}\text { As- } \\
\text { exposure }\end{array}$} & \multicolumn{6}{|c|}{ Dependent variable LINE-1 methylation (\%) } \\
\hline & \multicolumn{2}{|l|}{ All subjects $^{a}$} & \multicolumn{2}{|l|}{ Males $^{b}$} & \multicolumn{2}{|l|}{ Females $^{c}$} \\
\hline & Unadjusted & Adjusted & Unadjusted & Adjusted & Unadjusted & Adjusted \\
\hline \multicolumn{7}{|l|}{ Water As } \\
\hline$R^{2}$ & 0.033 & 0.057 & 0.003 & 0.018 & 0.079 & 0.085 \\
\hline$\Delta R^{2}$ & 0.024 & & 0.015 & & 0.006 & \\
\hline $95 \% \mathrm{Cl}$ & $-0.241,-0.043$ & $-0.238,-0.038$ & $-0.161,0.085$ & $-0.178,0.076$ & $-0.410,-0.088$ & $-0.407,-0.081$ \\
\hline$p$-value & $<0.01$ & $<0.01$ & 0.539 & 0.428 & $<0.01$ & $<0.01$ \\
\hline \multicolumn{7}{|l|}{ Hair As } \\
\hline$R^{2}$ & 0.019 & 0.045 & 0.003 & 0.019 & 0.043 & 0.053 \\
\hline$\Delta R^{2}$ & 0.009 & & 0.016 & & 0.010 & \\
\hline $95 \% \mathrm{Cl}$ & $-0.378,-0.014$ & $-0.382,-0.014$ & $-0.282,0.150$ & $-0.318,0.129$ & $-0.662,-0.038$ & $-0.664,-0.037$ \\
\hline$p$-value & $<0.05$ & $<0.05$ & 0.545 & 0.406 & $<0.05$ & $<0.05$ \\
\hline \multicolumn{7}{|l|}{ Nail As } \\
\hline$R^{2}$ & 0.054 & 0.079 & 0.016 & 0.031 & 0.100 & 0.106 \\
\hline$\Delta R^{2}$ & 0.025 & & 0.015 & & 0.006 & \\
\hline $95 \% \mathrm{Cl}$ & $-0.595,-0.179$ & $-0.591,-0.175$ & $-0.469,0.079$ & $-0.490,0.066$ & $-0.862,-0.236$ & $-0.858,-0.224$ \\
\hline$p$-value & $<0.001$ & $<0.001$ & 0.162 & 0.134 & $<0.01$ & $<0.01$ \\
\hline
\end{tabular}

Log-transformed values of arsenic concentrations were used

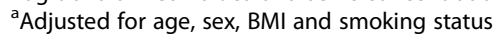

${ }^{\mathrm{b}}$ Adjusted for age, BMI and smoking status

${ }^{\mathrm{C}}$ Adjusted for age and BMI 


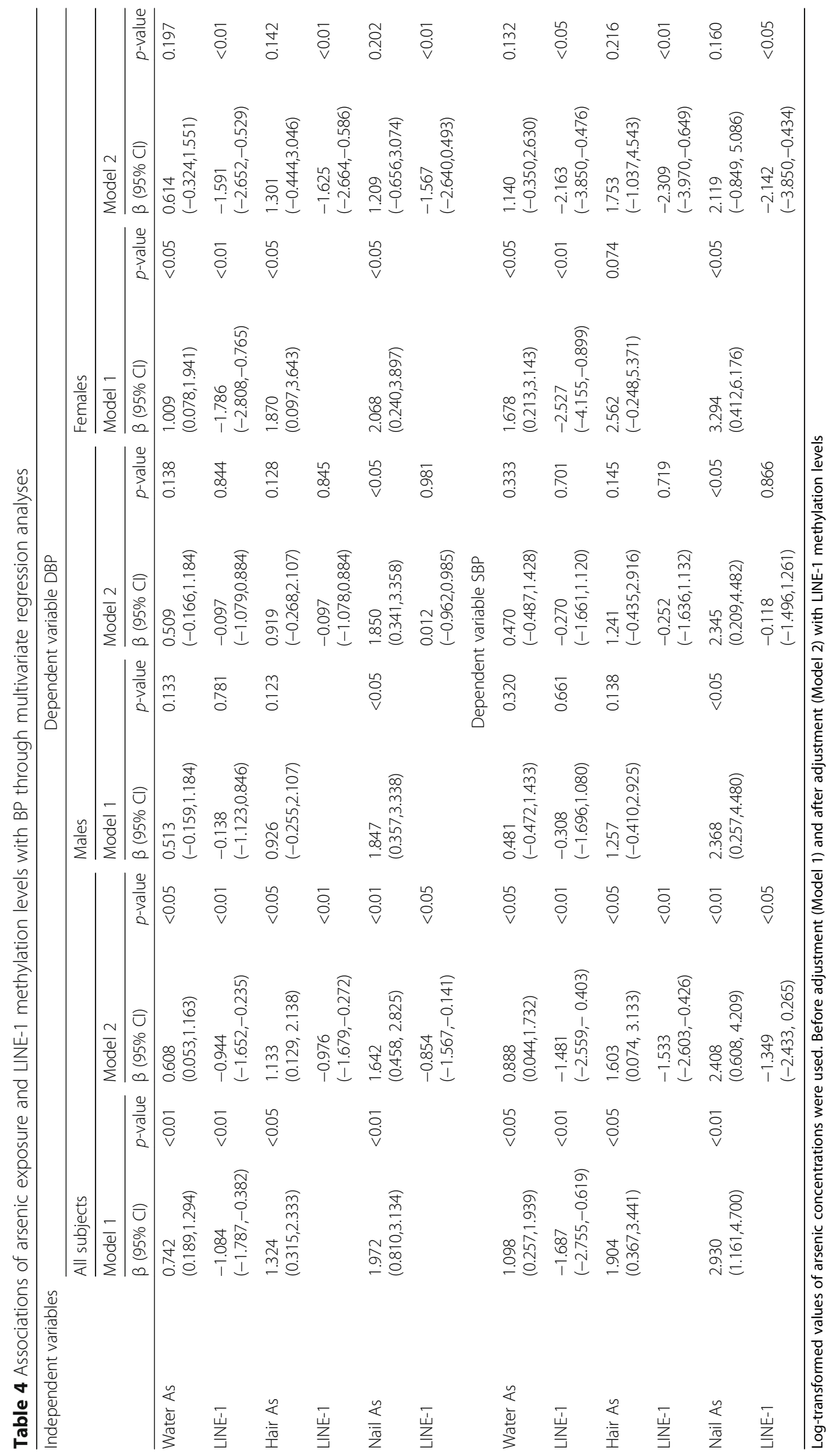




\section{Discussion}

In this study, we explored the association between arsenic exposure, as measured by drinking water, hair and nail arsenic concentrations, and LINE-1 methylation levels through a cross sectional study recruiting human subjects from arsenic-endemic and non-endemic areas in Bangladesh. We also examined whether the altered methylation levels were associated to arsenic exposurerelated elevated levels of BP. The results demonstrated that the LINE-1 methylation levels were significantly lower among individuals living in arsenic-endemic areas compared to those in non-endemic areas (Table 2). The drinking water, hair and nail arsenic concentrations of the female subjects showed significant negative associations with LINE-1 methylation levels (Table 3). On the contrary, no significant associations of arsenic exposure metrics with LINE-1 methylation levels were observed in the males, suggesting that the apparent associations between arsenic exposure and LINE-1 hypomethylation in all subjects may be a reflection of the significant association in females (Table 3). In addition, the arsenic exposure metrics in the females showed significant positive associations with $\mathrm{BP}$. Intriguingly, interaction analyses revealed that the arsenic-related elevated levels of BP were correlated with LINE-1 hypomethylation levels (Table 4).

A good number of studies using cell lines and experimental animals have been conducted to evaluate the effects of arsenic exposure on global DNA methylation [39-48]. Human studies have also revealed the effects of arsenic exposure on DNA methylation status, but the specific alterations are not consistently observed. By conducting a methylation incorporation assay, Pilsner et al. [24] showed that the plasma arsenic and urinary arsenic levels of their subjects were negatively correlated with the extent of $\left[{ }^{3} \mathrm{H}\right]$-methyl incorporation, suggesting that arsenic exposure was positively associated genomic methylation levels of blood leukocyte DNA. In another study, the same group (2009) [25] reported that arsenicexposed individuals with skin lesions had lower levels of methylation in DNA than the arsenic-exposed individuals without skin lesions. Majumdar et al. [21] observed an association between genome-wide hypermethylation and drinking water arsenic levels, in a population of only 64 individuals. In a gene-specific analysis, Hossain et al. [30] found that urinary arsenic was positively associated with the methylation of a tumor suppressor gene, $p 16$. In the same study, they did not observed an association between urinary arsenic and LINE-1 methylation. In a study of neonates in Bangladesh, Kile et al. [31] identified a positive association between maternal urinary total arsenic and LINE-1 methylation levels in both the mother and newborns. Pilsner et al. [29] obtained similar results in their study of mother-newborn pairs in Bangladesh; however, in their sex-specific analyses, the associations between arsenic exposures and ALU, LINE1 and LUMA were positive among the male newborns but negative among the female newborns (although the results were not significant). In contrast, Broberg et al. [32] reported that early prenatal arsenic exposure appears to decrease DNA methylation in boys but not in girls. It is not yet clear how long the alteration in the methylation status in DNA is stable or what the consequences of the neonatal alteration of DNA methylation will be in later life. Niedzwiecki et al. [23] reported that arsenic exposure was not associated with global 5methyl cytosine (MC) levels or 5-hydroxyl methyl cytosine $(\mathrm{hmC})$ levels in their complete subject population, but in their sex-specific analyses, they observed a positive association between arsenic exposure and global 5$\mathrm{hmC}$ levels in the males and a negative association in the females. The female-specific LINE-1 hypomethylation revealed in our present study partially agrees with the findings of Niedzwiecki et al.'s study. The discrepancies in the results from one study to another may be due to differences in arsenic doses, exposure times, the repetitive elements of DNA targeted for measuring global methylation levels, and nutritional or other confounding factors influencing the effects of arsenic exposure. Most of the previous studies did not demonstrate the biological consequences of the relationships between arsenic exposure and changes in DNA methylation, and thus there are great uncertainties regarding the pathophysiological consequences of the arsenic-induced alteration of methylation status in DNA.

Against this background, our present data demonstrating an association between arsenic exposure and reduced levels of LINE-1 methylation and their interactions with elevated levels of BP are noteworthy. Recent studies have shown a link between the decreased methylation levels in global and specific DNAs with CVD-related events [5, 49]. Castro et al. [50] reported lower DNA methylation levels in peripheral blood leukocytes from patients with atherosclerotic disease. It was also reported that a lower blood LINE-1 methylation level is a predictive factor for the incidences and mortalities of ischemic heart disease and stroke [5]. Bellavia et al. [51] showed an association between particulatematter-mediated hypomethylation and BP. Similar to the results of our previous research [18, 35, 37], in the present study we also observed that the average levels of $\mathrm{BP}$ and the percentage of hypertensive patients were higher in the arsenic-endemic areas compared to the non-endemic area, and the average levels of SBP and the percentage of hypertensive patients were higher in the females than the males in the arsenic-endemic areas (Table 2).

Intriguingly, in our multivariate regression analysis, the significance of the associations of arsenic exposure 
metrics with DBP and SBP disappeared in the female subjects after the adjustment for LINE-1 methylation levels, indicating that LINE-1 hypomethylation might be involved in an arsenic-related elevation of BP (Table 4). These results are in line with those of studies that showed a link between LINE-1 hypomethylation and CVD, especially hypertension $[16,50,51]$. It should be noted here that sex differences are also known to be present in other diseases caused by chronic exposure to arsenic. For example, women have been found to have higher risks of arsenic-related kidney, lung and bladder cancers as well as diabetes compared to men [14, 52-54]. The higher susceptibility of arsenic-exposed females to hypomethylation in DNA observed in the present study may also be associated with the higher incidences of those diseases in females compared to males.

Demographic and lifestyle characteristics such as age, sex, BMI, smoking, and alcohol consumption may be associated with global DNA methylation. However, the reports- regarding the effects of these characteristics are inconsistent $[17,26,55]$. In our regression analyses, we did not consider alcohol consumption as a variable because none of the subjects admitted to drinking alcohol. Before and after the adjustment for covariates (age, sex, BMI and smoking), significance levels of the associations between arsenic exposure and LINE-1 hypomethylation were not considerably different in the females, which indicated that age, sex and BMI had little or almost no effects on the associations. These results are consistent with those reported by Cash et al. [56]. In our study, the majority $(65.60 \%)$ of the male subjects were not smokers and no females were smokers. In the selection process of the present study, we excluded older individuals ( $>60$ years old). The narrow ranges of age (IQR: $28-$ 43.70 years) and BMI (IQR: 18.25-22.57) and the smaller number of smokers may explain why we did not observe any confounding effects of those variables on LINE-1 methylation status.

Since a variety of factors are involved in the development of hypertension, it seems unlikely that the epigenetic regulation of global genes is a sole factor causing hypertension in individuals living in arsenicendemic areas. To eliminate the confounding effects of age, sex, BMI, and smoking on the associations of arsenic exposure and LINE-1 methylation with BP, we performed further regression analyses (Additional file 1), and we found that arsenic exposure and LINE-1 hypomethylation retained their significant association with BP after the adjustment for those variables. These results suggest that arsenic exposure and LINE-1 hypomethylation may be important contributors to the elevation of BP.

It remains unknown why females are more susceptible to arsenic-induced LINE-1 hypomethylation than males.
One possibility is that higher levels and more consistent exposure to arsenic through drinking water in females than males may make females more susceptible to LINE-1 hypomethylation. Our female subjects (most of whom are housewives) may depend more on arseniccontaminated tube-well water at home than the males (most of whom are farmers), who work outside their homes. The average concentrations of drinking water in arsenic-endemic areas were higher in the females than males, although the significance of the difference was borderline $(p=0.056)$ (Table 2). However, this result may not be enough to draw a conclusion, because the differences in hair and nail arsenic concentrations which are more important indicators of the body's accumulation of arsenic - were not significant between the males and females. Another possible explanation for female susceptibility to LINE-1 hypomethylation is the effects of sex hormones. Cell line experiments demonstrated that the methylation levels of LINE-1 were decreased by treatment with estradiol but not with dihydrotestosterone [57]. Arsenic exposure has been reported to have endocrine-disruptive effects [58, 59], and it may thus be likely that arsenic causes hypomethylation through its endocrine-disrupting activity.

The strength of the present study was that we examined three types of exposure metrics (drinking water, hair and nail arsenic concentrations), and all indicators including external (drinking water) and internal (hair and nail) exposure metrics showed significant negative associations with the levels of LINE-1 methylation in the female subjects (Tables 3). Hypomethylation in the LINE-1 sequence across the three exposure metrics may exclude the potential bias in the observed associations.

However, our study has some limitations that should be carefully evaluated. First, although we detected significant differences in hypomethylation in LINE-1 between the residents of the arsenic-endemic and nonendemic areas, the absolute values were very small. The differences in LINE-1 methylation levels in the females were within $2 \%$ between the arsenic-endemic and nonendemic areas (Tables 2). Similar to our results, however, small but significant differences in global DNA methylation were reported to be associated with the risk of head and neck squamous cell carcinoma $(74.7 \%$ in cases vs. $75.3 \%$ in controls [60] and Alzheimer disease (AD);AD: $83.6 \% 5 \mathrm{mC}$, volunteers: $83.1 \% 5 \mathrm{mC}, p=0.05$ ) [61]. Moreover, recently published data showed that a small reduction in LINE-1 methylation significantly increased the risk of coronary heart disease in a Chinese population [17]. All of these results support the notion that a small difference in global genomic DNA methylation could be involved in the pathogenesis of several diseases including CVD.

Second, the nutritional status of our subjects which were not considered in this study may have affected the 
levels of global DNA methylation. It was suggested that the folate nutritional status may alter the methylation of DNA [24]. Third, we examined the LINE-1 methylation in blood leukocyte DNA, but it remains unclear whether the leukocytes' DNA reflects the effects of arsenic exposure on other organs such as skin, liver, bladder, kidney, spleen and lung. Although growing evidence has suggested global DNA hypomethylation in peripheral blood leukocytes as a biomarker for cancer and CVD, an organ-specific DNA methylation status may be more important to understand organ-specific effects and health outcomes caused by chronic exposure to arsenic.

Because of their wide distribution in genomic DNA, the methylation levels of LINE-1 have been used as a proxy for global DNA methylation status [62-64]. Methylation at LINE-1 repeats is gaining increasing attention as a surrogate marker to distinguish normal from pathological disease tissue [57]. Decreased methylation of LINE-1 sequences in blood leukocyte DNA has been documented in many human cancers and other chronic diseases [12-16] Therefore, LINE-1 hypomethylation in blood leukocyte-derived DNA caused by chronic exposure to arsenic may be one of the potential epigenetic mechanisms of arsenic-induced chronic diseases, including hypertension.

\section{Conclusions}

Our data demonstrated that chronic exposure to arsenic is significantly associated with global DNA hypomethylation measured in LINE-1 repeats in the blood leukocyte DNA; this association is more pronounced in females than males. We also observed a significant interaction of arsenic-related elevated levels of BP with LINE-1 hypomethylation, which indicates the possible involvement of LINE-1 hypomethylation in chronic arsenic exposurerelated hypertension in females. A large prospective study is required to test these observations.

\section{Additional file}

Additional file 1: Adjusted associations of arsenic exposure metrics and LINE-1 methylation levels with BP through multivariate regression analyses. (DOC $67 \mathrm{~kb})$

\section{Abbreviations \\ BP: Blood pressure; CVD: Cardiovascular disease; DBP: Diastolic blood pressure; LINE-1: Long interspersed nuclear element-1; SBP: Systolic blood pressure}

\section{Acknowledgements}

Not applicable.

\section{Funding}

This work was supported by the Ministry of Science and Technology, Government of the People's Republic of Bangladesh (Grant No. 39.009.006.01.00.042.2012-2013/ES-21/558); the National Institute for Environmental Studies, Japan (\#1415AI001, \#12237); a grant for
Environmental Research Projects from the Sumitomo Foundation, Japan; and a JSPS Kakenhi, Japan (Grant No.24406009). The funders had no role in the study design, data collection and analysis, decision to publish, or preparation of the manuscript.

\section{Availability of data and materials}

Data can be requested and obtained by contacting the corresponding author.

\begin{abstract}
Authors' contributions
$\mathrm{KH}$ oversaw the research, including study design, implementation, data collection and interpretation and drafting the manuscript. TS was involved in the laboratory experiment and data analysis. MMH and MSI and TT were participated in statistical analyses and interpretation of the results. AR and SKP, MR assisted in acquisition of data, initial analysis and carried out laboratory experiments. SH, ZAS and FN coordinated sample and data collections, and revised the manuscript. HM was involved in exposure assessment and analysis. $\mathrm{SH}$ was involved in the critical review of the manuscript. KN designed, supervised and coordinated the experiments related to pyrosegencing. All authors read and approved the final manuscript.
\end{abstract}

\section{Competing interests}

The authors declare that they have no competing interests.

Consent for publication

We have obtained consent from the subjects to publish their data.

\section{Ethics approval and consent to participate}

Ethical permission was obtained from the Institutional Animal, Medical Ethics, Biosafety and Biosecurity Committee (IAMEBBC) for experimentation on Animal, Human, Microbes and Living Natural Sources from The University of Rajshahi, Institute of Biological Sciences, Bangladesh (\#32/320-IAMEBBC/IBSc), and National Institute for Environmental Studies in Japan (\#2013-2R). The human subjects who participated in this study gave their written consent.

\section{Publisher's Note}

Springer Nature remains neutral with regard to jurisdictional claims in published maps and institutional affiliations.

\section{Author details \\ ${ }^{1}$ Department of Biochemistry and Molecular Biology, University of Rajshahi, Rajshahi-6205, Bangladesh. ${ }^{2}$ Center for Health and Environmental Risk Research, National Institute for Environmental Studies, Tsukuba 305-8506, Japan. ${ }^{3}$ Department of Applied Nutrition and Food Technology, Islamic University, Kushtia-7003, Bangladesh. Exim Bank Agricultural University, Chapainawabganj, Bangladesh. ${ }^{5}$ Laboratory of Molecular Nutrition and Toxicology, Faculty of Pharmaceutical Sciences, Tokushima Bunri University, Tokushima 770-8514, Japan.}

Received: 6 October 2016 Accepted: 1 March 2017

Published online: 07 March 2017

\section{References}

1. Chen JW, Chen HY, Li WF, Liou SH, Chen CJ, Wu JH, et al. The association between total urinary arsenic concentration and renal dysfunction in a community-based population from central Taiwan. Chemosphere. 2011;84:17-24.

2. Meliker JR, Wahl RL, Cameron LL, Nriagu JO. Arsenic in drinking water and cerebrovascular disease, diabetes mellitus, and kidney disease in Michigan: a standardized mortality ratio analysis. Environ Health. 2007;6:4.

3. Tapio S, Grosche B. Arsenic in the aetiology of cancer. Mutat Res. 2006;612:215-46.

4. Smith $\mathrm{AH}$, Lingas EO, Rahman M. Contamination of drinking-water by arsenic in Bangladesh: a public health emergency. Bull World Health Organ. 2000;78:1093-103.

5. Baccarelli A, Wright R, Bollati $V$, Litonjua A, Zanobetti A, Tarantini L, et al. Ischemic heart disease and stroke in relation to blood DNA methylation. Epidemiology. 2010;21:819-28.

6. Benard A, van de Velde CJ, Lessard L, Putter H, Takeshima L, Kuppen PJ, et al. Epigenetic status of LINE-1 predicts clinical outcome in early-stage rectal cancer. Br J Cancer. 2013;109:3073-83. 
7. Martín-Núñez GM, Rubio-Martín E, Cabrera-Mulero R, Rojo-Martínez G, Olveira G, Valdés $\mathrm{S}$, et al. Type 2 diabetes mellitus in relation to global LINE1 DNA methylation in peripheral blood: a cohort study. Epigenetics. 2014:9:1322-8.

8. Park JC, Hahn NM. Bladder cancer: a disease ripe for major advances. Clin Adv Hematol Oncol. 2014;12:838-45.

9. Senthong A, Kitkumthorn N, Rattanatanyong P, Khemapech N, Triratanachart S, Mutirangura A. Differences in LINE-1 methylation between endometriotic ovarian cyst and endometriosis-associated ovarian cancer. Int J Gynecol Cancer. 2014;24:36-42.

10. Kim JK, Samaranayake M, Pradhan S. Epigenetic mechanisms in mammals. Cell Mol Life Sci. 2009;66:596-612.

11. Schulz WA, Steinhoff C, Florl AR. Methylation of endogenous human retroelements in health and disease. Curr Top Microbiol Immunol. 2006:310:211-50.

12. Bae JM, Shin SH, Kwon HJ, Park SY, Kook MC, Kim YW, et al. ALU and LINE-1 hypomethylations in multistep gastric carcinogenesis and their prognostic implications. Int J Cancer. 2012;131:1323-31.

13. Moore LE, Pfeiffer RM, Poscablo C, Real FX, Kogevinas M, Silverman D, et al. Genomic DNA hypomethylation as a biomarker for bladder cancer susceptibility in the Spanish Bladder Cancer Study: a case-control study. Lancet Onco. 2008;19:359-66.

14. Wilhelm CS, Kelsey KT, Butler R, Plaza S, Gagne L, Zens MS, et al. Implications of LINE1 methylation for bladder cancer risk in women. Clin Cancer Res. 2010;16:1682-9.

15. Kim M, Long TI, Arakawa K, Wang R, Yu MC, Laird PW. DNA methylation as a biomarker for cardiovascular disease risk. PLoS ONE. 2010;5:9692.

16. Muka T, Koromani F, Portilla E, O'Connor A, Bramer WM, Troup J, et al. The role of epigenetic modifications in cardiovascular disease: a systematic review. Int J Cardiol. 2016;212:174-83.

17. Wei L, Liu S, Su Z, Cheng R, Bai X, Li X. LINE-1 hypomethylation is associated with the risk of coronary heart disease in Chinese population. Arq Bras Cardiol. 2014;102:481-8.

18. Huda N, Hossain S, Rahman M, Karim MR, Islam K, Mamun AA, et al. Elevated levels of plasma uric acid and its relation to hypertension in arsenic-endemic human individuals in Bangladesh. Toxicol Appl Pharmacol. 2014;281:11-8

19. Rahman M, Tondel M, Ahmad SA, Chowdhury IA, Faruquee MH, Axelson O. Hypertension and arsenic exposure in Bangladesh. Hypertension. 1999;33:74-8.

20. Tajuddin SM, Amaral AF, Fernández AF, Rodríguez-Rodero S, Rodríguez RM, Moore LE, et al. Spanish Bladder Cancer/EPICURO Study Investigators. Genetic and non-genetic predictors of LINE-1 methylation in leukocyte DNA. Environ Health Perspect. 2013;121:650-6.

21. Majumdar S, Chanda S, Ganguli B, Mazumder DN, Lahiri S, Dasgupta UB. Arsenic exposure induces genomic hypermethylation. Environ Toxicol. 2010;25:315-8

22. Niedzwiecki MM, Hall MN, Liu X, Oka J, Harper KN, Slavkovich V, et al. A dose response study of arsenic exposure and global methylation of peripheral blood mononuclear cell DNA in Bangladeshi adults. Environ Health Perspect. 2013;121:1306-12.

23. Niedzwiecki MM, Liu X, Hall MN, Thomas T, Slavkovich V, llievski V, et al. Sexspecific associations of arsenic exposure with global DNA methylation and hydroxymethylation in leukocytes: results from Two studies in Bangladesh. Cancer Epidemiol Biomarkers Prev. 2015;24:1748-57.

24. Pilsner JR, Liu X, Ahsan H, llievski V, Slavkovich V, Levy D, et al. Genomic methylation of peripheral blood leukocyte DNA: influences of arsenic and folate in Bangladeshi adults. Am J Clin Nutr. 2007;86:1179-86.

25. Pilsner JR, Liu X, Ahsan H, llievski V, Slavkovich V, Levy D, et al. Folate deficiency, hyperhomocysteinemia, low urinary creatinine, and hypomethylation of leukocyte DNA are risk factors for arsenic-induced skin lesions. Environ Health Perspect. 2009;117:254-60.

26. Lambrou A, Baccarelli A, Wright RO, Weisskopf $M$, Bollati $V_{\text {, }}$ Amarasiriwardena C, Vokonas P, Schwartz J, et al. Arsenic exposure and DNA methylation among elderly men. Epidemiology. 2012;23:668-76.

27. Bandyopadhyay AK, Paul S, Adak S, Giri AK, et al. Reduced LINE-1 methylation is associated with arsenic-induced genotoxic stress in children. Biometals. 2016;29:731-41.

28. Tellez-Plaza M, Tang WY, Shang Y, Umans JG, Francesconi KA, Goessler W, et al. Association of global DNA methylation and global DNA hydroxymethylation with metals and other exposures in human blood DNA samples. Environ Health Perspect. 2014;122:946-54.
29. Pilsner JR, Hall MN, Liu X, llievski V, Slavkovich V, Levy D, et al. Influence of prenatal arsenic exposure and newborn sex on global methylation of cord blood DNA. PLoS One. 2012;7:e37147.

30. Hossain MB, Vahter M, Concha G, Broberg K. Environmental arsenic exposure and DNA methylation of the tumor suppressor gene p16 and the DNA repair gene MLH1: effect of arsenic metabolism and genotype. Metallomics. 2012;4:1167-75.

31. Kile ML, Baccarelli A, Hoffman E, Tarantini L, Quamruzzaman Q, Rahman M, et al. Prenatal arsenic exposure and DNA methylation in maternal and umbilical cord blood leukocytes. Environ Health Perspect. 2012;120:1061-6.

32. Broberg K, Ahmed S, Engström K, Hossain MB, Jurkovic Mlakar S, Bottai M, et al. Arsenic exposure in early pregnancy alters genome wide DNA methylation in cord blood, particularly in boys. J Dev Orig Health Dis. 2014;5:288-98.

33. Ali N, Hoque MA, Haque A, Salam KA, Karim MR, Rahman A, et al. Association between arsenic exposure and plasma cholinesterase activity: a population based study in Bangladesh. Environ Health. 2010;9:36.

34. Hossain E, Islam K, Yeasmin F, Karim MR, Rahman M, Agarwal S, et al. Elevated levels of plasma Big endothelin-1 and its relation to hypertension and skin lesions in individuals exposed to arsenic. Toxicol Appl Pharmacol. 2012;259:187-94.

35. Islam MS, Mohanto NC, Karim MR, Aktar S, Hoque MM, Rahman A, et al. Elevated concentrations of serum matrix metalloproteinase-2 and -9 and their associations with circulating markers of cardiovascular diseases in chronic arsenic-exposed individuals. Environ Health. 2015;14:92.

36. Karim MR, Salam KA, Hossain E, Islam K, Ali N, Haque A, et al. Interaction between chronic arsenic exposure via drinking water and plasma lactate dehydrogenase activity. Sci Total Environ. 2010;409:278-83.

37. Karim MR, Rahman M, Islam K, Mamun AA, Hossain S, Hossain E, et al. Increases in oxidized low-density lipoprotein and other inflammatory and adhesion molecules with a concomitant decrease in high-density lipoprotein in the individuals exposed to arsenic in Bangladesh. Toxicol Sci. 2013;135:17-25.

38. Rahman M, Mamun AA, Karim MR, Islam K, Amin HA, Hossain S, et al. Associations of total arsenic in drinking water, hair and nails with serum vascular endothelial growth factor in arsenic-endemic individuals in Bangladesh. Chemosphere. 2015;120:336-42

39. Benbrahim-Tallaa L, Waterland RA, Styblo M, Achanzar WE, Webber MM, Waalkes MP. Molecular events associated with arsenic-induced malignant transformation of human prostatic epithelial cells: aberrant genomic DNA methylation and K-ras oncogene activation. Toxicol Appl Pharmacol. 2005;206:288-98.

40. Chen H, Li S, Liu J, Diwan BA, Barrett JC, Waalkes MP. Chronic inorganic arsenic exposure induces hepatic global and individual gene hypomethylation: implications for arsenic hepato carcinogenesis. Carcinogenesis. 2004:25:1779-86.

41. Coppin JF, Qu W, Waalkes MP. Interplay between cellular methyl metabolism and adaptive efflux during oncogenic transformation from chronic arsenic exposure in human cells. J Biol Chem. 2008;283:19342-50.

42. Mauro M, Caradonna F, Klein CB. Dysregulation of DNA methylation induced by past arsenic treatment causes persistent genomic instability in mammalian cells. Environ Mol Mutagen. 2016:57:137-50.

43. Nohara K, Baba T, Murai H, Kobayashi Y, Suzuki T, Tateishi Y, et al. Global DNA methylation in the mouse liver is affected by methyl deficiency and arsenic in a sex-dependent manner. Arch Toxicol. 2011;85:653-61.

44. Okoji RS, Yu RC, Maronpot RR, Froines JR. Sodium arsenite administration via drinking water increases genome-wide and Ha-ras DNA hypomethylation in methyl-deficient C57BL/6 J mice. Carcinogenesis. 2002;23:777-85.

45. Reichard JF, Schnekenburger M, Puga A. Long term low dose arsenic exposure induces loss of DNA methylation. Biochem Biophys Res Commun. 2007;352:188-92.

46. Reichard JF, Puga A. Effects of arsenic exposure on DNA methylation and epigenetic gene regulation. Epigenomics. 2010;2:87-104.

47. Sciandrello G, Caradonna F, Mauro M, Barbata G. Arsenic-induced DNA hypomethylation affects chromosomal instability in mammalian cells. Carcinogenesis. 2004:25:413-7.

48. Waalkes MP, Liu J, Chen H, Xie Y, Achanzar WE, Zhou YS, et al. Estrogen signaling in livers of male mice with hepatocellular carcinoma induced by exposure to arsenic in utero. J Natl Cancer Inst. 2004;96:466-74.

49. Kim CS, Kim YR, Naqvi A, Kumar S, Hoffman TA, Jung SB, et al. Homocysteine promotes human endothelial cell dysfunction via site-specific epigenetic regulation of p66shc. Cardiovasc Res. 2011;92:466-75.

50. Castro R, Rivera I, Struys EA, Jansen EE, Ravasco P, Camilo ME, et al. Increased homocysteine and S-adenosylhomocysteine concentrations and DNA hypomethylation in vascular disease. Clin Chem. 2003;49:1292-6. 
51. Bellavia A, Urch B, Speck M, Brook RD, Scott JA, Albetti B, et al. DNA hypomethylation, ambient particulate matter, and increased blood pressure: findings from controlled human exposure experiments. J Am Heart Assoc. 2013;19:2.

52. Chen CJ, Chuang YC, Lin TM, Wu HY. Malignant neoplasms among residents of a Blackfoot disease-endemic area in Taiwan: high-arsenic artesian well water and cancers. Cancer Res. 1985;45:5895-9.

53. Smith AH, Hopenhayn-Rich C, Bates MN, Goeden HM, Hertz-Picciotto I Duggan HM, et al. Cancer risks from arsenic in drinking water. Environ Health Perspect. 1992;97:259-67.

54. Vahter M, Akesson A, Lidén C, Ceccatelli S, Berglund M. Gender differences in the disposition and toxicity of metals. Environ Res. 2007;104:85-95.

55. Zhu ZZ, Hou L, Bollati V, Tarantini L, Marinelli B, Cantone L, et al. Predictors of global methylation levels in blood DNA of healthy subjects: a combined analysis. Int J Epidemiol. 2010;41:126-39.

56. Cash HL, Tao L, Yuan JM, Marsit CJ, Houseman EA, Xiang YB, et al. LINE-1 hypomethylation is associated with bladder cancer risk among nonsmoking Chinese. Int J Cancer. 2012;130:1151-9.

57. El-Maarri O, Walier M, Behne F, van Üüm J, Singer H, Diaz-Lacava A, et al. Methylation at global LINE-1 repeats in human blood are affected by gender but not by age or natural hormone cycles. PLoS One. 2011;19:6.

58. Bae-Jump VL, Zhou C, Boggess JF, Gehrig PA. Arsenic trioxide (As2O3) inhibits expression of estrogen receptor-alpha through regulation of the mitogen-activated protein kinase (MAPK) pathway in endometrial cancer cells. Reprod Sci. 2008;15:1011-7.

59. Chatterjee A, Chatterii U. Arsenic abrogates the estrogen-signaling pathway in the rat uterus. Reprod Biol Endocrinol. 2010;8:80.

60. Hsiung DT, Marsit CJ, Houseman EA, Eddy K, Furniss CS, McClean MD, et al. Global DNA methylation level in whole blood as a biomarker in head and neck squamous cell carcinoma. Cancer Epidemiol Biomarkers Prev. 2007;16:108-14

61. Bollati V, Galimberti D, Pergoli L, Dalla Valle E, Barretta F, et al. DNA methylation in repetitive elements and Alzheimer disease. Brain Behav Immun. 2011;25:1078-83.

62. Bollati V, Baccarelli A, Hou L, Bonzini M, Fustinoni S, Cavallo D, et al. Changes in DNA methylation patterns in subjects exposed to low-dose benzene. Cancer Res. 2007:67:876-80.

63. Bollati V, Fabris S, Pegoraro V, Ronchetti D, Mosca L, Deliliers GL, et al. Differential repetitive DNA methylation in multiple myeloma molecular subgroups. Carcinogenesis. 2009;30:1330-5.

64. Tarantini A, Maitre A, Lefebvre E, Marques M, Marie C, Ravanat IL, et al. Relative contribution of DNA strand breaks and DNA adducts to the genotoxicity of benzo[a]pyrene as a pure compound and in complex mixtures. Mutat Res. 2009:671:67-75.

\section{Submit your next manuscript to BioMed Central and we will help you at every step:}

- We accept pre-submission inquiries

- Our selector tool helps you to find the most relevant journal

- We provide round the clock customer support

- Convenient online submission

- Thorough peer review

- Inclusion in PubMed and all major indexing services

- Maximum visibility for your research

Submit your manuscript at www.biomedcentral.com/submit
Biomed Central 